\title{
ANALISIS DAMPAK KEBIJAKAN MONETER TERHADAP VARIABEL MAKROEKONOMI DI INDONESIA (PENERAPAN VECTOR ERROR CORRECTION MODEL)
}

\author{
Oleh:
}

\author{
Umi Julaihah*)
}

\begin{abstract}
The objectives of this study are to analyze the effect of monetary policy on Indonesian economy and to know policy variable such as monetary aggregate that have contribution in explain the variability of macroeconomic variables.

The data sample used in this study are quarterly time series data from 1983.1 2003.2. Those data are base money, one month commercial bank deposit interest rate, consumer price index, gross domestic product, and exchange rate (rupiah/dollar). A method of analysis in this study is Vector Error Correction Model (VECM). The advantages of VECM are because it has: (i) impulse response function that can trace the response of one endogen variable because shock/innovation of others variables in the model; (ii) variance decomposition that can show the contribution of one variable endogen in explained the variability of others endogen variables.

The result of impulse response function shows that economic growth did not response the shock of base money. Although base money has significant effect on inflation but this model leaves a price puzzle and liquidity puzzle. The result of variance decomposition shows that base money contributes only 5\% on inflation but it did not give any contribution on economic growth fluctuation. The interesting result is policy variables (base money) have best contribution in explain the fluctuation on exchange rate. Then, it asserts that shock of policy variable is responded by exchange rate faster than other macroeconomic variables.
\end{abstract}

Key words: monetary policy, impulse response function, variance decomposition. 


\section{PENDAHULUAN}

\section{Latar Belakang}

Krisis ekonomi yang dimulai pada bulan Juli 1997 ternyata sempat menghancurkan perekonomian Indonesia. Indonesia yang dianggap sebagai salah satu the miracle of Asia ternyata tidak mampu mempertahankan keberhasilan tersebut. Namun, di sisi lain krisis sebenarnya memiliki keuntungan walaupun tidak direncanakan dan tidak diharapkan, yaitu mendorong untuk melakukan berbagai reformasi, khususnya di bidang ekonomi yang memungkinkan terjadinya perubahan kerangka hukum dan kelembagaan untuk menjalankan kebijakan moneter dan untuk mengamankan sistem keuangan Indonesia (Goeltom, 1999:355).

Indonesia telah membuat perubahan fundamental dalam kebijakan moneternya seiring dengan dikeluarkannya UU No. 23 Tahun 1999 tentang Bank Indonesia. Pertama, kebijakan moneter kini difokuskan untuk memelihara dan menjaga stabilitas rupiah. Kedua, pemberian independensi yang lebih besar kepada Bank Indonesia dalam menentukan target inflasi dan arah kebijakan moneternya. Ketiga, keputusan pemilihan kebijakan diserahkan pada Gubernur Bank Indonesia tanpa intervensi dari pemerintah dan lembaga lain. Empat, adanya akuntabilitas dan transparansi kebijakan moneter yang mewajibkan Bank Indonesia mengumumkan target inflasi dan rencana kebijakan moneter pada setiap permulaan tahun. Semua reformasi tersebut diharapkan mampu untuk mengeluarkan Indonesia dari krisis (Warjiyo dan Agung, 2002: 3-4).

Mengacu pada UU No. 23 Tahun 1999, maka terlihat bahwa kebijakan moneter diimplementasikan dengan menggunakan instrumen moneter (suku bunga ataupun agregat moneter) yang mempengaruhi sasaran antara untuk mencapai sasaran akhir, yaitu stabilitas harga. Kebijakan moneter selama ini pun dituntut untuk mencari paradigma baru mekanisme transmisi yang diharapkan mampu mengendalikan 'variabel kebijakan'. Berbagai studi telah dilakukan di Indonesia untuk mencari jalur transmisi mana yang dilalui oleh kebijakan moneter dalam mempengaruhi perekonomian. Mekanisme transmisi merupakan salah satu isu utama dalam kebijakan moneter. Selain itu, terdapat isu utama lain 
yang masih sering diperdebatkan yaitu "apakah kebijakan moneter memiliki dampak terhadap perekonomian?"

Bermula dari pertanyaan "apakah kebijakan moneter memiliki dampak terhadap kondisi perekonomian suatu negara?" maka muncullah berbagai penelitian yang memfokuskan pada analisis tentang dampak kebijakan moneter. Friedman mengatakan bahwa kebijakan moneter memang berdampak terhadap perekonomian, sedangkan Lucas menambahkan bahwa kebijakan moneter tersebut akan berdampak terhadap perekonomian jika kebijakan tersebut tidak diantisipasi oleh masyarakat. Perdebatan mengenai dampak kebijakan moneter terhadap perekonomian dimulai dari penelitian sederhana yang dilakukan oleh Friedman dan Schwartz (1963) dengan menggunakan korelasi sederhana antara uang dan output, sampai pada penggunaan model yang lebih kompleks seperti Kausalitas Granger dan pendekatan Vector Autoregression (VAR) yang diperkenalkan oleh Sims (1972) (Perez, 2003:1).

\section{Rumusan Masalah}

Berdasarkan paparan pada latar belakang, maka terlihat pentingnya pemahaman mengenai apakah kebijakan moneter memiliki dampak terhadap perekonomian mengingat tujuan kebijakan moneter adalah untuk menggerakkan perekonomian. Pemahaman tentang analisis kebijakan moneter akan menjadi lebih penting bagi Indonesia. Fokus pada penelitian ini adalah untuk melihat peran agregat moneter (M0) pada studi dampak kebijakan moneter.

\section{Tujuan Penelitian}

Rumusan tujuan penelitian yang hendak dicapai dalam penelitian ini adalah untuk mengetahui apakah kebijakan moneter yang selama ini dilakukan oleh otoritas moneter memiliki dampak terhadap performance perekonomian Indonesia, yang tercermin pada hubungan antara variabel kebijakan dengan variabel-variabel makroekonomi, 


\section{KAJIAN PUSTAKA}

\section{Landasan Teori}

Pemilihan variabel makroekonomi dalam penelitian ini dibentuk dari reduce form persamaan IS-LM-AS. Model tersebut memiliki 3 persamaan, yaitu fungsi permintaan agregat, fungsi permintaan uang, dan fungsi penawaran agregat. Meskipun model ini memiliki beberapa kelemahan, tapi setidaknya model ini cukup sederhana dan tegar. Model IS-LM-AS sebenarnya masih dapat dimodifikasi dengan melenturkan restriksi yang ada, sehingga modifikasi tersebut dapat mencerminkan kondisi pada dunia nyata (Holtemoller, 2001:5).

Persamaan IS menunjukkan kombinasi antara output dan suku bunga yang menunjukkan posisi keseimbangan di pasar barang:

$$
\mathrm{y}_{\mathrm{t}}=\mathrm{b}_{0}+\mathrm{b}_{1}\left[\mathrm{i}_{\mathrm{t}}-\left(\mathrm{E}_{\mathrm{t}-1} \mathrm{p}_{\mathrm{t}+1}-\mathrm{p}_{\mathrm{t}}\right)\right]+\xi_{\mathrm{t}}
$$

di mana $y_{t}$ dan $p_{t}$ adalah log dari output riil dan harga nominal, $i_{t}$ adalah suku bunga nominal, $\mathrm{b}_{1}<0$, dan $\mathrm{E}_{\mathrm{t}-1}$ menunjukkan expected value atas informasi pada $\mathrm{t}-1$. Suku bunga riil $\mathrm{i}_{\mathrm{t}}-\left(\mathrm{E}_{\mathrm{t}-1} \mathrm{p}_{\mathrm{t}+1}-\mathrm{p}_{\mathrm{t}}\right)$ memiliki dampak negatif pada $\mathrm{y}_{\mathrm{t}}$.

Hubungan LM menunjukkan kombinasi antara output dan suku bunga pada saat pasar uang dalam keseimbangan.

$$
\mathrm{m}_{\mathrm{t}}-\mathrm{p}_{\mathrm{t}}=\mathrm{c}_{0}+\mathrm{c}_{1} \mathrm{i}_{\mathrm{t}}+\mathrm{c}_{2} \mathrm{y}_{\mathrm{t}}+\eta_{\mathrm{t}}
$$

di mana $\mathrm{m}_{\mathrm{t}}$ adalah log persediaan uang, $\mathrm{c}_{1}<0$, dan $\mathrm{c}_{2}>0$. Dampak negatif dari suku bunga atas permintaan uang menunjukkan opportunity cost dari memegang uang, dan tanda positif dari $c_{2}$ ditunjukkan oleh motif transaksi dari memegang uang. Hubungan AS dapat diinterpretasikan sebagai expectation augmented Phillips curve:

$$
\mathrm{y}_{\mathrm{t}}=\mathrm{a}_{0}+\mathrm{a}_{1}\left(\mathrm{p}_{\mathrm{t}}-\mathrm{E}_{\mathrm{t}-1} \mathrm{p}_{\mathrm{t}+1}\right)+\mathrm{a}_{2} \mathrm{y}_{\mathrm{t}-1}+\zeta_{\mathrm{t}}
$$

di mana $\mathrm{a}_{1}>0$, dan $0<\mathrm{a}_{2}<1$. Gangguan $\zeta_{\mathrm{t}}, \eta_{\mathrm{t}}$, dan $\xi_{\mathrm{t}}$ adalah kejutan yang bebas dari lag seluruh variabel. Gangguan tersebut diinterpretasikan sebagai kejutan permintaan agregat, kejutan moneter, dan kejutan penawaran agregat.

Dari ketiga persamaan tersebut diperoleh reduce form variabel $\mathrm{p}, \mathrm{y}$, i. Di mana $\mathrm{p}$ adalah harga (tingkat inflasi), y adalah output (PDB), i adalah suku bunga. Variabel $\mathrm{m}$ adalah uang yang bersifat eksogen. Penambahan variabel nilai 
tukar dalam model yang akan dianalisis didasarkan pada asumsi Indonesia adalah negara yang terbuka - sebagaimana model Mundell-Fleming yang memasukkan nilai tukar pada analisa kebijakan moneter untuk perekonomian terbuka.

Penilitian ini menggunakan metode VAR/VECM, kelemahan dari metode ini adalah model yang dibentuk untuk mengestimasi adalah atheoritic. Guna mengurangi terjadinya model misspesification, maka akan ditunjukkan mekanisme transmisi dari model yang dipilih.

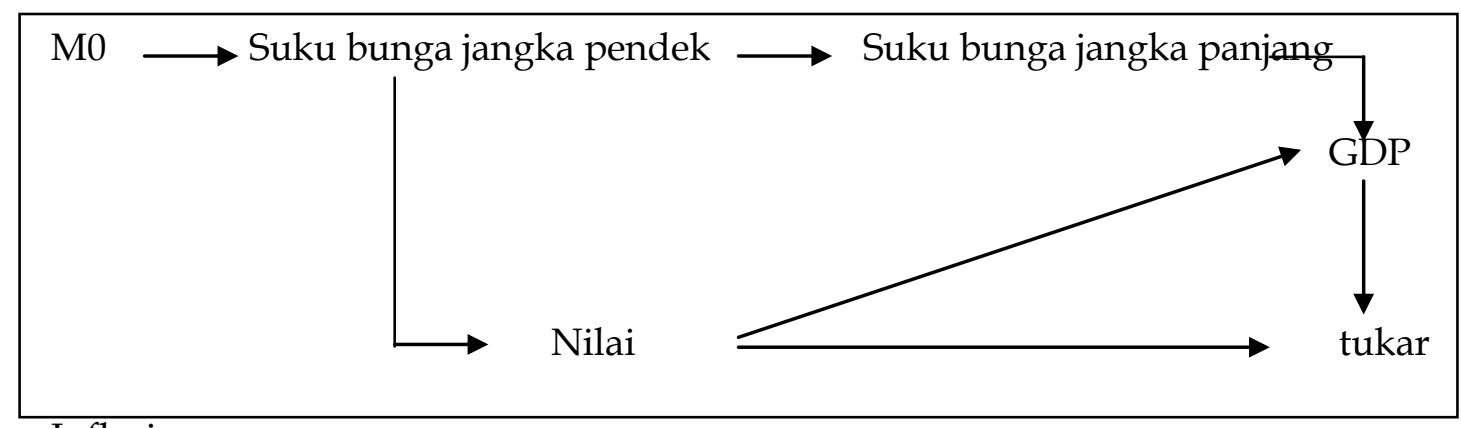

Inflasi

\section{Gambar 1.1 Mekanisme Transmisi Kebijakan Moneter}

\section{METODE PENELITIAN}

Data

Penelitian ini akan menggunakan time series data sekunder. Data penelitian dikumpulkan dari berbagai sumber, seperti Laporan Tahunan Bank Indonesia, Laporan Bank Indonesia, Statistik Ekonomi dan Keuangan Indonesia (SEKI), situs Bank Indonesia, situs Biro Pusat statistik (BPS), dan CD-room International Financial Statistics (IFS) IMF.

\section{Variabel dan Definisi Operasional}

Berikut dijelaskan tentang variabel yang digunakan dalam penelitian beserta definisi operasionalnya:

a. Jumlah uang primer (M0) adalah uang kartal, cadangan bank umum, saldo giro bank umum, saldo giro masyarakat. 
b. Suku bunga deposito (DEP1) adalah suku bunga deposito bank umum jangka waktu 1 (satu) bulan.

c. Tingkat inflasi adalah perubahan angka Indeks Harga Konsumen (IHK) riil atas harga konstan 1993.

d. Tingkat output (PDB) adalah nilai Produk Domestik Bruto riil Indonesia atas harga konstan tahun 1993

e. Nilai tukar (ER), data nilai tukar yang digunakan adalah nilai tengah mata uang rupiah terhadap dollar Amerika.

\section{Model Analisis}

Fokus pada penelitian ini adalah untuk melihat peran agregat moneter (M0) dan suku bunga (SBI) dalam studi dampak kebijakan moneter. Sebagaimana model yang digunakan oleh Fung (2002), maka spesifikasi model yang akan digunakan dalam penelitian ini adalah:

$$
\mathrm{Y}_{\mathrm{t}}=\sum \mathrm{B}_{\mathrm{i}} \mathrm{Y}_{\mathrm{t}-1}+\sum \mathrm{C}_{\mathrm{i}} \mathrm{P}_{\mathrm{t}-1}+\mathrm{AyV}_{\mathrm{t}} \mathrm{y}
$$

$\mathrm{P}_{\mathrm{t}}=\sum \mathrm{D}_{\mathrm{i}} \mathrm{Y}_{\mathrm{t}-1}+\sum \mathrm{G}_{\mathrm{i}} \mathrm{P}_{\mathrm{t}-1}+\mathrm{ApV}_{\mathrm{t}} \mathrm{p}^{\mathrm{s}}$

di mana $B_{i}, C_{i}, D_{i}, G_{i}, A p$ merupakan koefisien matrik. Persamaan (2.1) dan (2.2) terbagi menjadi dua kelompok, yaitu blok bukan kebijakan (Y) dan blok kebijakan $(\mathrm{P})$. Vektor $\mathrm{Y}_{\mathrm{t}}$ berisi variabel makroekonomi bukan kebijakan seperti PDB, inflasi, suku bunga deposito 1 bulan, dan nilai tukar. Vektor $P_{t}$ meliputi variabel kebijakan atau moneter yang potensial digunakan sebagai indikator kebijakan moneter, seperti M0 dan suku bunga SBI.

Dengan asumsi bahwa inovasi terhadap variabel blok kebijakan tidak mempengaruhi variabel bukan kebijakan dalam periode $\mathrm{C}_{\mathrm{o}}=0$, persamaan (2.1) dan (2.2) dapat ditulis dalam standar reduce form VAR dengan mengkelompokkan $\mathrm{Y} t$ dan $\mathrm{P} t$ pada sisi kiri. Bila $\mathrm{U}_{\mathrm{t}} \mathrm{y}$ menjadi residual yang menghubungkan pada blok $\mathrm{Y}$ dan $\mathrm{U}_{\mathrm{t}} \mathrm{p}$ menjadi komponen residual yang menghubungan pada blok $\mathrm{P}$ adalah orthogonal terhadap $\mathrm{U}_{\mathrm{t}} \mathrm{y}$. Kemudian persamaan (2.1) dan (2.2) dapat ditulis sebagai reduce form VAR untuk estimasi: 
$\mathrm{Y}_{\mathrm{t}}=\sum \mathrm{H}_{\mathrm{i}}$ y $\mathrm{Y}_{\mathrm{t}-1}+\sum \mathrm{H}_{\mathrm{i}} \mathrm{p} \mathrm{P}_{\mathrm{t}-1}+\mathrm{U}_{\mathrm{t}}^{\mathrm{y}}$

...(2.3)

$\mathrm{P}_{\mathrm{t}}=\sum \mathrm{J}_{\mathrm{i}} \mathrm{y} \quad \mathrm{Y}_{\mathrm{t}-1}+\sum \mathrm{J}_{\mathrm{i}} \mathrm{p} \mathrm{P}_{\mathrm{t}-1}+\left[\left(\mathrm{I}-\mathrm{G}_{0}\right)^{-1} \mathrm{D}_{0} \mathrm{U}_{\mathrm{t}} \mathrm{y}+\mathrm{U}_{\mathrm{t}} \mathrm{p}\right]$

Setelah mengestimasi (2.3) dan (2.4), komponen residual dari (2.4) adalah orthogonal terhadap (2.3), ditunjukkan oleh $\mathrm{U}_{\mathrm{t}} \mathrm{p}$. Membandingkan persamaan (2.3) dan (2.4) terhadap (2.1) dan (2.2), dapat dilihat bahwa $\mathrm{U}_{t} \mathrm{p}$ berhubungan dengan $\mathrm{V}_{\mathrm{t}} \mathrm{p}$ :

$$
\mathrm{U}_{\mathrm{t}} \mathrm{p}=\left(\mathrm{I}-\mathrm{G}_{0}\right)^{-1} \mathrm{ApV}_{\mathrm{t}}^{\mathrm{p}}
$$

Dengan menetapkan estimasi parameter, kejutan struktural, $\mathrm{V}_{\mathrm{t}} \mathrm{p}$, memasukkan kejutan kebijakan moneter, $\mathrm{v}^{\mathrm{s}}$, maka akan didapat:

$$
\mathrm{V}_{\mathrm{t}} \mathrm{p}=(\mathrm{Ap})^{-1}\left(\mathrm{I}-\mathrm{G}_{0}\right) \mathrm{U}_{\mathrm{t}} \mathrm{p}
$$

Respon dinamis dari seluruh variabel terhadap kejutan kebijakan kemudian dapat dianalisis melalui fungsi impulse response.

Penelitian ini menggunakan model VAR/VECM, dengan menggunakan variabel independen: M0 (sebagai variabel kebijakan) dan variabel dependen: DEP1, IHK, PDB, dan ER.

\section{HASIL DAN PEMBAHASAN}

\section{Deskripsi Data}

Bagian ini akan membahas mengenai pola keterkaitan antarvariabel yang digunakan dalam model. Pembahasan disajikan dalam bentuk grafik, keuntungan dari tahap ini adalah agar diperoleh gambaran tentang pola perilaku dan keterkaitan antarvariabel dalam model.

Pada gambar 3.1 menunjukkan hubungan antara M0, IHK, dan PDB (kesemuanya dalam bentuk log). Dari gambar 3.1 terlihat bahwa M0, IHK, dan PDB memiliki tren yang sama. Pada awal tahun 1990 dan pertengahan 1998, 
terlihat bahwa terjadi penurunan inflasi yang cukup tajam. Kondisi tersebut dimungkinkan terjadi akibat adanya kebijakan moneter ketat yang dilaksanakan oleh otoritas moneter untuk mengatasi inflasi dan krisis ekonomi tahun 1997.

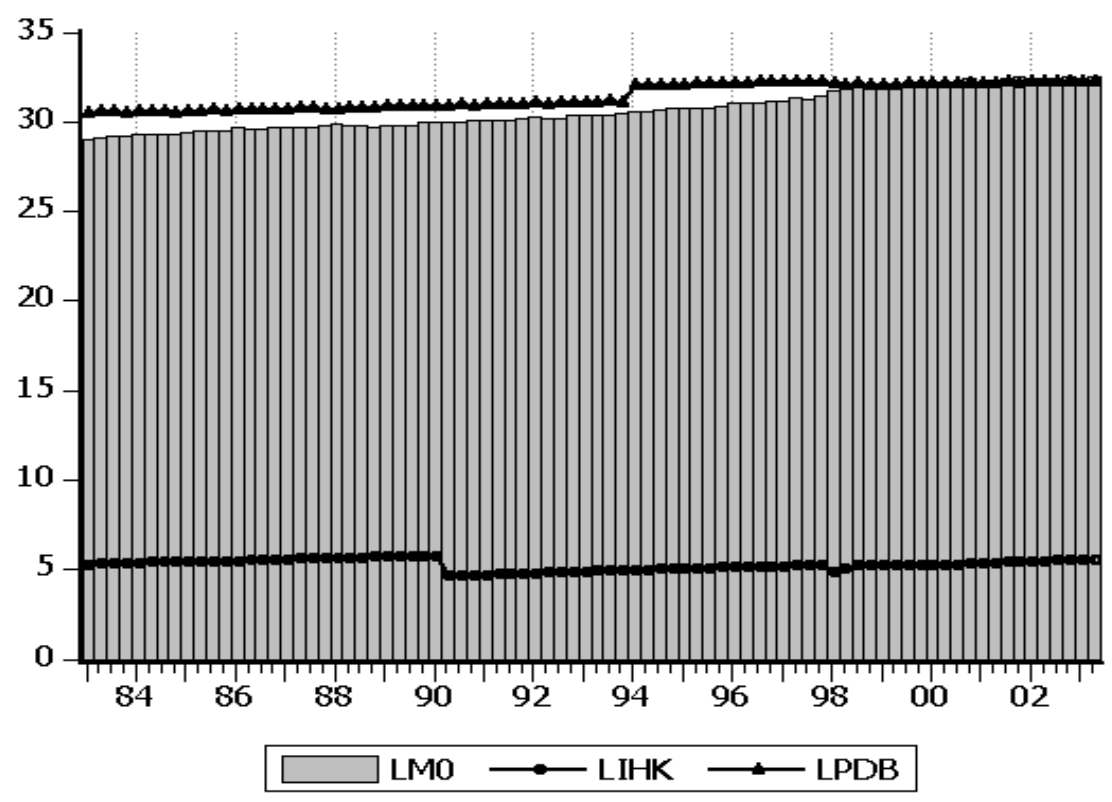

\section{Gambar 3.1 Perkembangan M0, Inflasi dan Pertumbuhan}

Pada gambar 3.2 menunjukkan hubungan antara nilai tukar (ER), IHK, dan PDB. Pada saat sebelum krisis 1997, fluktuasi nilai tukar (ER) kurang direspon oleh IHK dan PDB. Namun, ketika post crisis, ER terlihat sebagai leading indicator atas pergerakan IHK dan PDB.

Gambar 3.2 Perkembangan Nilai Tukar, Inflasi, dan Pertumbuhan 


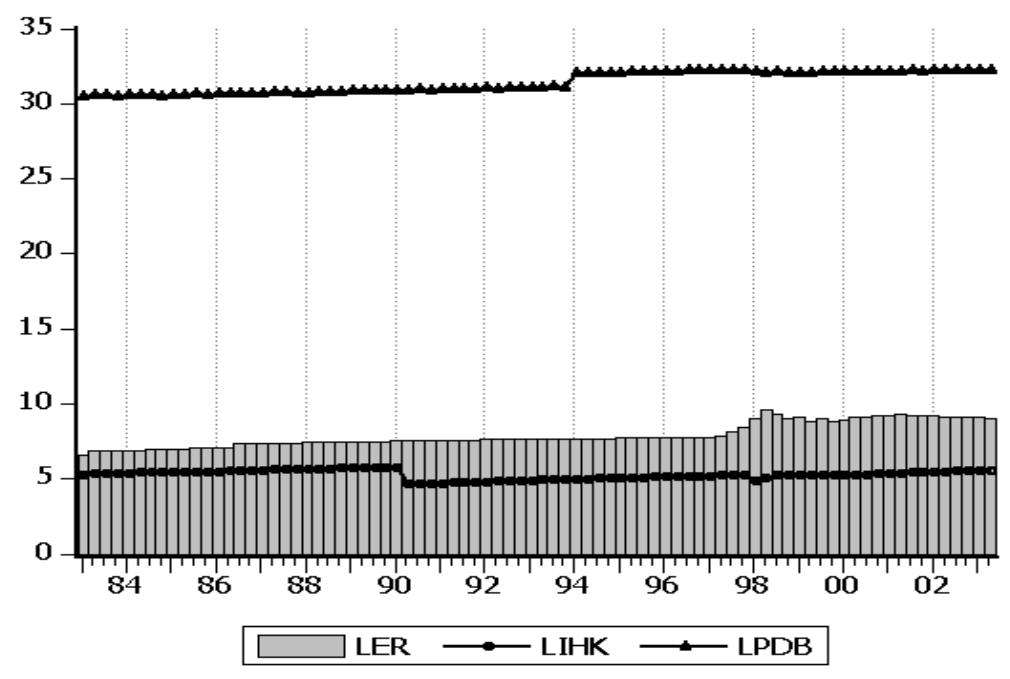

\section{Hasil Analisis}

\section{Uji Stasioneritas Data}

Permasalahan yang sering muncul dalam analisis time series adalah permasalahan mengenai stasioneritas data. Hal ini perlu diperhatikan karena variabel yang tidak stasioner akan menghasilkan regresi lancung. Regresi lancung terjadi ketika hasil regresi menunjukkan hubungan yang signifikan antarvariabel padahal hal tersebut tidak lain adalah hubungan contemporaneous dan tidak memiliki makna kausal (Harris, 1995: 14).

Berdasarkan hasil uji akar-akar unit pada tabel 3.1, diketahui bahwa tidak seluruh data stasioner pada level, namun setelah dilakukan differencing, maka seluruh data telah stasioner.

Tabel 3.1 Uji Akar-Akar Unit

\begin{tabular}{ccc}
\hline Variabel & $\begin{array}{c}\text { Level } \\
\text { (ADF stat) }\end{array}$ & $\begin{array}{c}\text { First Difference } \\
\text { (ADF stat) }\end{array}$ \\
\hline LMO & 0,5252 & $-3,4682$ \\
DEP1 & $-3,3836$ & $-5,4804$ \\
LIHK & $-1,8211$ & $-4,0737$ \\
LPDB & $-0,7869$ & $-3,7411$ \\
LER & $-0,7619$ & $-4,1218$ \\
\hline
\end{tabular}

Keterangan: Nilai kritis $1 \%:-3,5164$ 
$5 \%:-2,8991$

$10 \%:-2,5865$

\section{Uji Kointegrasi Johansen}

Setelah mengetahui karakteristik masing-masing data yang akan digunakan dalam penelitian, di mana konsistensi jangka panjang dari model analisis dapat diketahui melalui uji kointegrasi Johansen. Hubungan saling mempengaruhi dapat dilihat dari kointegrasi yang terjadi antarvariabel itu sendiri. Jika terdapat kointegrasi antarvariabel, maka hubungan saling mempengaruhi berjalan secara menyeluruh dan informasi tersebar secara pararel.

Tabel 3.2 menunjukkan adanya satu vektor kointegrasi, atau setidaknya terdapat satu kombinasi linier independen dari variabel-variabel yang terdapat dalam model tersebut. Konsekuensinya adalah hipotesa alternatif yang menyatakan ada hubungan kointegrasi dapat diterima.

Tabel 3.2 Uji Kointegrasi

\begin{tabular}{ccccc}
\hline Ho:r & $\begin{array}{c}\text { Eigenvalue } \\
\left(\lambda_{\mathrm{i}}\right)\end{array}$ & $\begin{array}{c}\text { Trace } \\
\text { Statistic }\end{array}$ & $\begin{array}{c}\boldsymbol{\Lambda}_{\text {trace }} \\
(\mathbf{9 5 \%})\end{array}$ & $\begin{array}{c}\boldsymbol{\Lambda}_{\text {trace }} \\
(\mathbf{9 9 \%})\end{array}$ \\
\hline 0 & 0,417143 & 82,68856 & 68,52 & 76,07 \\
1 & 0,238679 & 41,12292 & 47,21 & 54,46 \\
2 & 0,124044 & 20,12500 & 29,68 & 35,65 \\
3 & 0,115162 & 9,927206 & 15,41 & 20,04 \\
4 & 0,006552 & 0,506191 & 3,76 & 6,65 \\
\hline
\end{tabular}

Pengujian stasioneritas data dan kointegrasi ini juga sangat penting jika dikaitkan dengan alat analisis yang akan digunakan dalam penelitian ini. Setelah diketahui bahwa data tidak stasioner namun berkointegrasi, maka model VAR yang akan digunakan selanjutnya adalah VECM, karena jika data yang digunakan tidak stasioner dan masih menggunakan VAR, maka estimasi yang dihasilkan memang konsisten tapi bias (tidak efisien). 


\section{Estimasi Model VECM}

Sebelum mengaplikasikan dan menganalisis model VECM - sebagaimana juga model VAR - maka perlu ditentukan panjang lag. Isu tentang penentuan panjang lag juga semakin penting seiring dengan anggapan bahwa pemilihan lag yang tepat akan menghasilkan residual bersifat Gaussian (terbebas dari permasalahan autokorelasi dan heteroskedastisitas) (Gujarati, 2003: 853; Enders, 1989: 313; Harris, 1995: 81). Penentuan lag pada penelitian ini didasarkan pada pendekatan stok, yaitu $\mathrm{k}=\mathrm{N}^{1 / 3}$. Jadi, lag yang akan digunakan pada penelitian ini adalah lag 4 dengan pertimbangan bahwa lag 4 sudah cukup untuk mencakup sistem dinamis yang menggunakan data kwartalan.

Perilaku dinamis dari model VAR/VECM dapat dilihat melalui respon dari setiap variabel endogen terhadap kejutan pada variabel tersebut maupun terhadap variabel endogen lainnya. Ada dua cara untuk dapat melihat karakteristik dinamis model VAR, yaitu melalui impulse response function dan variance decomposition.

\section{Impulse response function}

Seluruh impulse response dari disajikan pada gambar 3.4, tapi hanya impulse response yang berkaitan dengan kejutan variabel kebijakan yang akan dibahas.

Pada gambar 3.4, adanya kejutan uang primer dapat diartikan bahwa otoritas moneter melakukan kebijakan moneter yang ekspansif, yang kemudian direspon positif oleh uang primer. Hal ini memang logis karena dengan asumsi otoritas menggunakan agregat moneter sebagai variabel kebijakan, maka kebijakan moneter ekspansif dapat dilihat dari adanya penambahan agregat moneter tersebut.

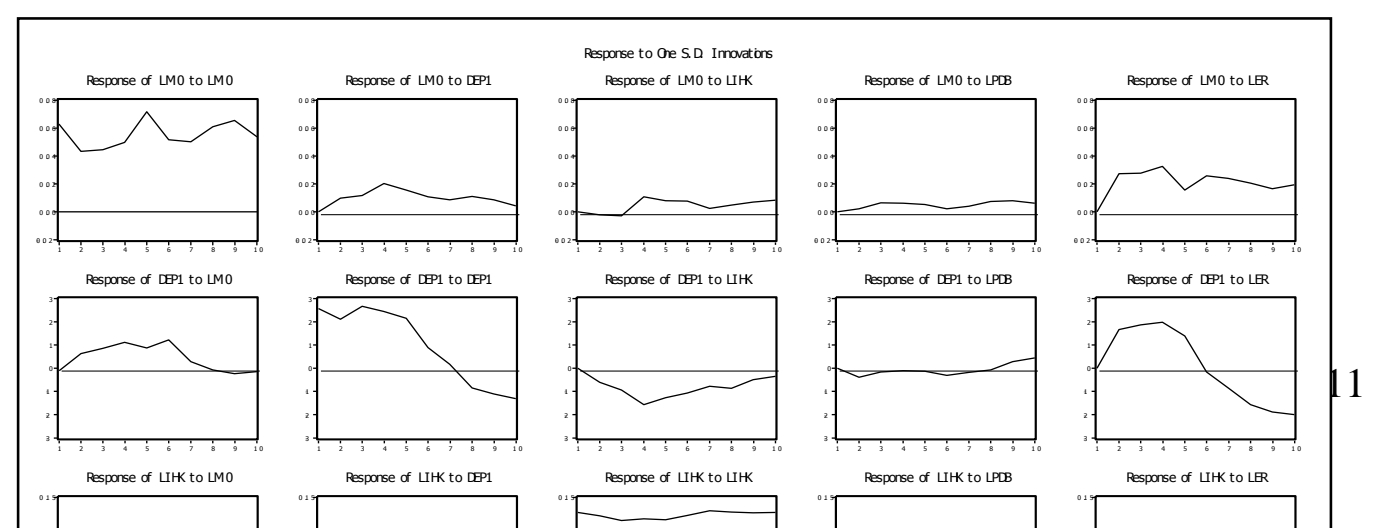




\section{Gambar 3.4 Impulse Response}

Pada model ini terlihat adanya liquidity puzzle, yaitu kebijakan moneter yang ekspansif diikuti oleh kenaikan suku bunga di pasar uang. Liquidity puzzle menunjukkan adanya respon tidak negatif dari suku bunga terhadap adanya kejutan positif dari agregat moneter atau dapat juga dianggap bahwa terjadi liquidity puzzle jika tidak terdapat liquidity effect.

Interpretasi ekonomi yang bisa digunakan untuk menjelaskan liquidity puzzle tersebut adalah pada saat otoritas moneter menerapkan kebijakan yang ekspansif dengan menambah jumlah uang primer, kemudian otoritas memiliki keyakinan bahwa akan terjadi kenaikan inflasi. Adanya ekspektasi mengenai kenaikan inflasi menyebabkan otoritas mengambil keputusan untuk menaikkan suku bunga sebagai cara untuk meredam kenaikan inflasi yang akan datang.

Pada model ini juga terdapat fenomena price puzzle, di mana kebijakan moneter yang ekspansif akan diikuti oleh adanya penurunan laju inflasi atau sebaliknya, ketika terjadi kontraksi moneter diikuti dengan kenaikan laju inflasi. Interpretasi dari fenomena tersebut adalah pada saat otoritas melakukan kebijakan ekspansif dengan menambah uang primer, penambahan uang primer tersebut tidak disalurkan pada masyarakat (uang kartal) melainkan untuk 
menambah cadangan bank umum (Giro Wajib Minimum). Sehingga penambahan uang primer tidak berdampak pada sektor riil (peningkatan laju inflasi) melainkan diserap dalam Giro Wajib Minimum (GWM).

Laju pertumbuhan yang tidak merespon ekspansi moneter bukanlah berarti tidak terjadi pertumbuhan riil, pertumbuhan tetap ada namun dengan laju pertumbuhan yang tetap seperti periode sebelum terjadinya ekspansi moneter. Hal ini dimungkinkan, sebagaimana yang terjadi pada respon inflasi terhadap penambahan uang primer (penambahan uang primer tersebut tidak disalurkan pada masyarakat (uang kartal) melainkan untuk menambah GWM sehingga penambahan uang primer tidak berdampak pada sektor riil.

Respon nilai tukar yang positif terhadap adanya ekspansi moneter dapat dijelaskan sebagai berikut: penambahan uang primer jika diserap oleh masyarakat, maka akan dapat meningkatkan jumlah uang beredar. Kenaikan jumlah uang beredar berdampak terdepresiasinya nilai tukar dalam negeri (diperlukan rupiah yang lebih banyak untuk mendapatkan dollar).

\section{Variance decomposition}

Setelah menganalisis perilaku dinamis melalui impulse response, selanjutnya akan dilihat karakteristik model melalui variance decomposition. Pada tabel 3.5 menunjukkan variance decomposition dari model yang dipilih. Ada beberapa hal yang dapat diamati dari tabel 3.5 Pertama, kontribusi dari LM0 sangatlah kecil dalam menjelaskan variabilitas LPDB, yaitu sekitar 0,07\% sampai 0,25\%. Kedua, variabilitas LIHK hanya mampu dijelaskan sebesar 5\% oleh kejutan LM0 dan ini dicapai pada jangka menengah. Sedangkan pada jangka panjang kemampuan LM0 dalam menjelaskan LIHK semakin berkurang. Ketiga, LM0 memberi kontribusi terbesar dalam menjelaskan pergerakan LER sampai $21 \%$.

Hasil variance decomposition juga dapat dilihat pada gambar 3.5. Pada gambar 3.5 terlihat bahwa LM0 hanya berkontribusi sangat kecil terhadap pergerakan LIHK bahkan kontribusi LM0 terhadap LPDB sangat kecil. Hasil ini menunjukkan bahwa LM0 tidak mampu menjelaskan variabilitas LPDB. 
Tabel 3.5 Variance Decomposition

\begin{tabular}{cccccccc}
\hline \multirow{2}{*}{$\begin{array}{c}\text { Variabel } \\
\text { Dependen }\end{array}$} & Horizon & S.E & \multicolumn{5}{c}{ Dijelaskan oleh kejutan } \\
\cline { 4 - 7 } & & & LM0 & DEP1 & LIHK & LPDB & LER \\
\hline LM0 & 2 & 0,081414 & 87,22548 & 1,418098 & 0,090025 & 0,065223 & 11,20117 \\
& 6 & 0,151069 & 78,87971 & 4,342466 & 1,071963 & 0,490002 & 15,21586 \\
& 10 & 0,195897 & 81,69307 & 3,311888 & 1,009370 & 0,712756 & 13,27292 \\
\hline DEP1 & 2 & 3,831884 & 2,795773 & 75,00527 & 2,599556 & 0,985429 & 18,61398 \\
& 6 & 7,269868 & 8,725345 & 55,54753 & 12,26964 & 0,570079 & 22,88742 \\
& 10 & 8,336266 & 6,866882 & 47,56541 & 11,80682 & 0,879185 & 32,88170 \\
\hline LIHK & 2 & 0,182640 & 4,393444 & 0,762654 & 94,69726 & 0,028261 & 0,118380 \\
& 6 & 0,311478 & 5,339213 & 1,780416 & 91,20707 & 0,043881 & 1,629419 \\
& 10 & 0,410550 & 4,579455 & 1,971532 & 91,83558 & 0,026140 & 1,587293 \\
\hline LPDB & 2 & 0,139821 & 0,071943 & 3,554405 & 0,159428 & 95,98871 & 0,225512 \\
& 6 & 0,248955 & 0,164171 & 10,33343 & 0,855748 & 87,12120 & 1,525453 \\
& 10 & 0,330084 & 0,251517 & 12,00931 & 1,640661 & 84,37194 & 1,726580 \\
\hline LER & 2 & 0,180212 & 10,68234 & 19,35847 & 1,687125 & 0,424785 & 67,84729 \\
& 6 & 0,322224 & 17,39722 & 23,14370 & 0,572654 & 1,588311 & 57,29812 \\
& 10 & 0,358376 & 21,78678 & 20,37698 & 0,588904 & 1,773500 & 55,47384 \\
\hline
\end{tabular}




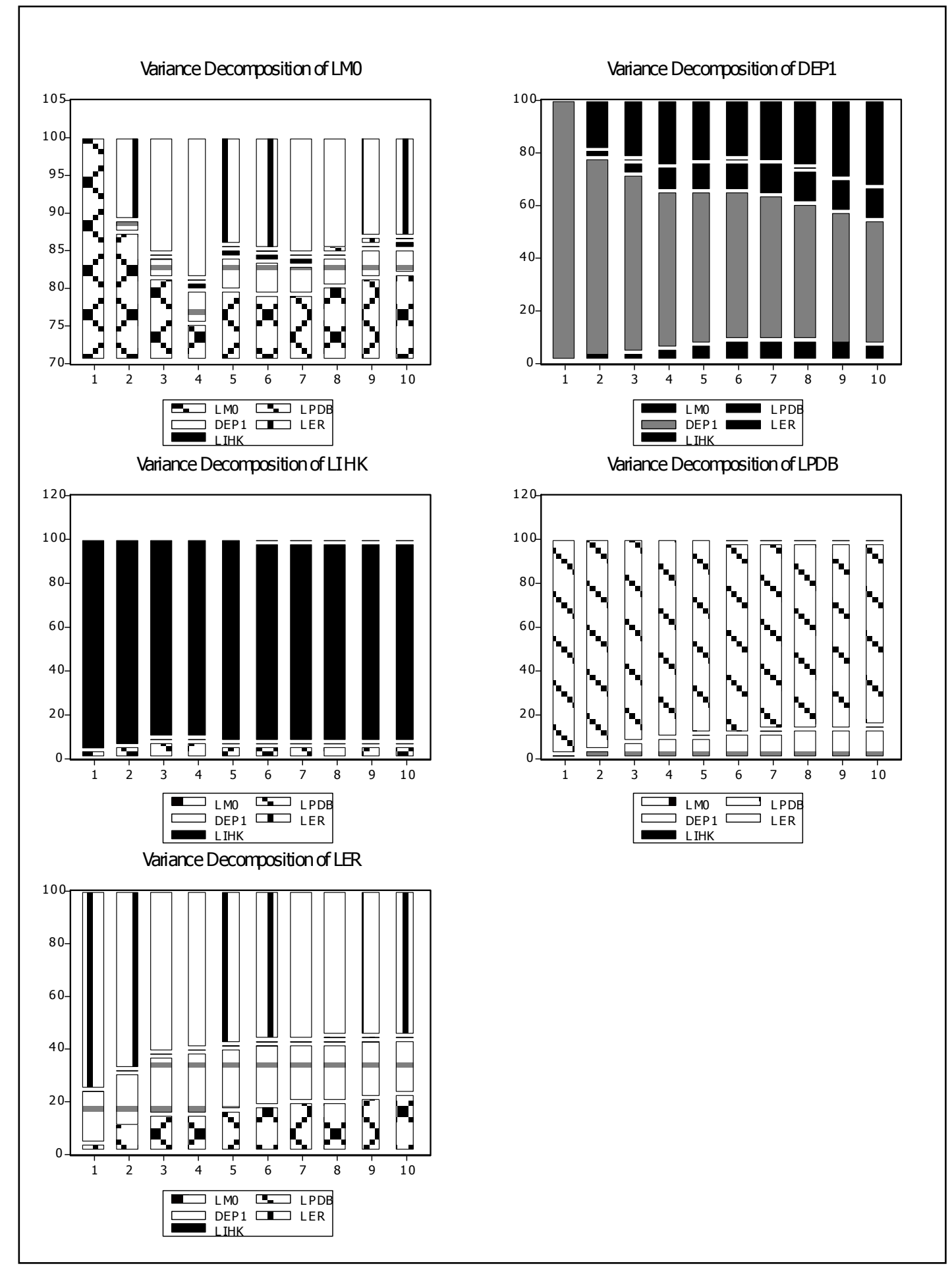

Gambar 3.5 Variance Decomposition Model 1 


\section{Kesimpulan}

a. Berdasarkan hasil impulse response yang menunjukkan bahwa pertumbuhan ekonomi tidak merespon adanya kejutan satu standar deviasi dari uang primer. Sedangkan pengaruh kejutan uang primer terhadap inflasi yang terlihat cukup signifikan, ternyata menghasilkan prize puzzle. Prize puzzle merupakan kondisi dimana ekspansi moneter yang dilakukan oleh otoritas moneter ternyata direspon dengan penurunan inflasi. Penggunaan agregat moneter untuk kasus di Indonesia ternyata hanya berdampak pada inflasi dan tidak memiliki pengaruh terhadap pertumbuhan ekonomi.

b. Berdasarkan variance decomposition, maka terlihat bahwa uang primer tidak mampu memberikan kontribusi terhadap variasi pertumbuhan ekonomi, uang primer hanya berkontribusi terhadap variabilitas inflasi sebesar $5 \%$. Sedangkan respon dari nilai tukar sebesar $10 \%$ hingga $22 \%$. Jadi, dapat disimpulkan bahwa adanya kejutan kebijakan moneter ternyata direspon secara cepat oleh nilai tukar dibandingkan dengan variabel-variabel ekonomi makro yang lain.

\section{Saran}

a. Beberapa anjuran untuk mulai beralih pada price-based approach hendaknya dipertimbangkan oleh otoritas moneter. Kondisi ini didukung oleh semakin banyak hasil-hasil penelitian yang menunjukkan bahwa quantity-based approach dengan menggunakan agregat moneter semakin lemah dalam mempengaruhi inflasi dan pertumbuhan ekonomi.

b. Otoritas moneter hendaknya lebih berhati-hati dalam menetapkan kebijakannya karena perubahan kecil dari official rate akan berdampak sangat besar terhadap nilai tukar dan dampak ini akan persisten. Perubahan nilai tukar pada akhirnya juga sangat berpengaruh pada posisi perdagangan internasional Indonesia dan posisi cadangan devisa Indonesia. 


\section{DAFTAR PUSTAKA}

Enders, Walter, 1989, Applied Econometric Time Series, John Wiley \& Son, New York.

Fung, Ben C., 2002, "A VAR Analysis of the Effect of Monetary Policy in East Asia," BIS Working Paper, No. 119.

Gujarati, Damodar, 2003, Basic Econometric, Third Edition, McGrawHill, Singapore.

Harris, Richard, 1995, Cointegration Analysis in Econometric Modelling, Prentice Hall, New York

Haug, Alfred A., Ozer Karagedikli, dan Satish Ranchhod, 2003, "Monetary Policy Transmission Mechanism and Currency Unions: A Vector Error Correction Method Approach to a Trans-Tasman Currency Union," Journal of Economic Literature Classification Number: C32, E50, E52.

Holtemoller, Oliver, 2001, "Structural Vector Autoregressive Models and Nonetary Policy Analysis," Journal of Economic Literature, Classification Number: C32, E52, pp.166.

Kusmiarso, Bambang, Elisabeth Sukawati, Sudiro Pambudi, Dadal Angkoro, Andry Prasmuko, and Iss Savitri Hafidz, 2002, "Interest Rate Channel of Monetary Transmission in Indonesia," Perry Warjiyo and Juda Agung (eds.): Transmission Mechanism of Monetary Policy in Indonesia. Strategic Research Program of the Directorate of Economic Research and Monetary Policy, Directorate of Economic Research and Monetary Policy, Bank Indonesia,

Mishkin, Frederic S., 1996, "What Monetary Policy Can and Cannot Do," Conference on Monetary Policy in Transition in East and West: Strategies, Instruments and Transmission Mechanism, November 17-19, Vienna.

Mishkin, Frederic S., 2001, The Economics of Money, Banking, and Financial Market, sixth edition, Addison Wesley Longman.

Monetary Policy Committee (MPC) Bank of England Staff, 1999, The Transmission Mechanism of Monetary Policy, Bank of England.

Sarwono, Hartadi A. dan Perry Warjiyo, 1998, "Mencari Paradigma Baru Manajemen Moneter dalam Sistem Nilai Tukar Fleksibel: Suatu Pemikiran untuk Penerapannya di Indonesia," Buletin Ekonomi Moneter dan Perbankan, Vol. 1, No. 1, Juli, hal. 5-23.

Sims, A. Christopher, 1991, "Interpreting the Macroeconomic Time Series Facts: The Effect of Monetary Policy," European Economic Review, Vol. 36, No. 5, pp. 1-18. 
Stark, Tom dan Heb Taylor, 1991, "Activist Monetary Policy for Good or Evil? The New Keynesian vs. the New Classicals," Bussiness Review, Federal Reserve Bank of Philadelphia, March/April, pp. 17-91.

Vinals, Jose dan Javier Valles, 1999, "On the Real Effect of Monetery Policy: A Central Banker's View," Oesterreichsche Nationalbank Working Paper No. 38, Juli, pp. 841. (http://www2.oenb.co.at/workpaper/wp38.pdf)

Warjiyo, Perry dan Doddy Zulverdi, 1998, "Penggunaan Suku Bunga sebagai Sasaran Operasional Kebijakan Moneter di Indonesia," Buletin Ekonomi Moneter dan Perbankan. Vol. 1, No. 1, hal. 25-58.

Warjiyo, Perry, F.X. Sugiyono, Suseno, Hotbin Sigalingging, Iskandar, Ascarya, Suarpika Bimantoro, Piter Abdullah, Solikin, 2003, Bank Indonesia: Bank Sentral Republik Indonesia Tinjauan Kelembagaan, Kebijakan, dan Organisasi, Pusat Pendidikan dan Studi Kebanksentralan (PPSK) Bank Indonesia, Jakarta.

*) Umi Julaihah, SE., M.Si, Dosen Jurusan IPS Fakultas Tarbiyah UIN Malang 